\title{
ARBITRAJE, TUTELA CAUTELAR E IMPARCIALIDAD “OBJETIVA" DEL JUZGADOR: UN TEMA PARA EL DEBATE
}

Eugenia Ariano Deho

Resumen

En el presente artículo, se desarrolla el tema del arbitraje desde una perspectiva analítica, explicando su origen, así como su finalidad y posibles problemas que podrían suscitarse. Por otro lado, se intenta explicar su origen de acuerdo a los estándares intemacionalmente aceptados y el respectivo análisis a nivel nacional para determinar si es que efectivamente se está llevando a cabo siguiendo estos parámetros. Se explica además que se origina en el ámbito comercial, con la finalidad de evitar inoportunas "injerencias" de los órganos judiciales que puedan llegar a comprometer el buen éxito del arbitraje, que tiene como naturaleza la resolución de conflictos de manera ágil y eficiente. Se discute hasta qué punto se desenvuelve la tutela cautelar en materia arbitral, y hasta qué medida es admisible la libertad en este tipo de resolución de conflictos, así como las garantías que tienen que respetarse, en todo proceso, incluido el arbitraje.

\section{Summary}

This article develops the subject of arbitration with an analytical perspective, explaining the origin, scope. purpose andpotential problems thal couldarise. On the other hand, it explain the origin of arbitration according to the international accepted standards as a national analysis of the situation of the arbitration in order to determine if indeed it is being carried out according to international paramelers. It further explains that it is originated in the commercial field, in order to avoid inappropriate "interference " of the courts that could compromise the success of arbitration, which is know by nature as a quickl and ejficient resolution fot conflicts. It discusses the extension to which interim protection operates in arbitration, and how permissible is the freedom in this type of conflict resolution, and the guarantees thal must be respected in all processes, incltding arbitration.

\section{Sommaire}

Cet article développe le sujel de I 'arbitrage dans une perspective analytique, en expliquant son origine, le but et les prohlémes polenliels qtti pourraient survenir. D un aulre colé s 'explique son origine d'accord aux normes internationalement acceptées et il se fait un analyse afín de déterminer si en ejfei il est réalisé actuellemenl en utilisant les paramétres internationaux. En outre, il s 'explique que son origine vient du domaine commercial, afin d'éviter une "ingérence» inappropriée des tribunaux qui pourraient compromettre le sttccés de I 'arbitrage, qui é, par nature un mécanisme rapide et efficace pour ia résoudre des conflicts. Se discute a qttel point est admissible la prolection provisoire que opere dans l'arbitrage et dans quelle mesure la liberté est permise dans ce type de résolution des conflits, aussi la protection provisoire que opere dans I 'arbitrage. Einalemenl I'article développe $i$ 'aspect des garandes qui doivent étre respectés dans tous Ies processus y compris i arbitrage. 


\section{PREMISA}

En las últimas décadas del pasado siglo se registraron dos notorias tendencias "globales": por un lado, la exaltación de la tutela cautelar cual componente esencial de un sistema de tutela jurisdiccional de los derechos $y$, como tal, constitucionalmente asegurada $^{1} \mathrm{y}$, por el otro, la atribución de potestades cautelares a los árbitros, cual auténtica "conquista para el sistema" arbitral".

Está por verse si la tendencia "global" de atribuir funciones cautelares a los árbitros es o no consecuencia de la (Ilamada) "constitucionalización" de la tutela cautelar ${ }^{3}$, pero lo cierto es que un tanto en todos lados - como se verá- existe ya la convicción de que es "inherente" a la función arbitral el que los árbitros cuenten con potestades cautelares.

Sin embargo, entre los tantos problemas que suscita la atribución de potestades cautelares a los árbitros se encuentra uno que desde hace algún tiempo me ronda por la cabeza: ¿La determinación del (llamado) fumus boni iuris implica un "adelanto de opinión" que inhabilita al que lo realizó para resolver el fondo de la controversia?

A este interrogante suele darse respuesta negativa. Yo misma, hace algunos años, criticando aquella disposición del art. 612 CPC que (¿Freudianamente?) señala que "toda medida cautelar importa un prejuzgamiento", adhiriéndome a la communis opinio, sostuve que "cuando de lo que se trata es conceder o no una pretendida tutela cautelar el juez no «prejuzga», sino que «juzga» si en el caso concreto se verifican los presupuestos de dicha tutela. Lo que el juez debe «juzgar» es si es posible y probable que el demandante de la cautela tenga la razón (en el mérito), pero ese juicio sobre el derecho (o en general, sobre una concreta situación jurídica reconocida y tutelada por el derecho sustancial) del que el actor se afirma titular no implica de ninguna manera un «adelanto de opinión» sobre el fondo" ${ }^{4}$.

1 A partir de la famosa Sentencia No 190-85 de la Corte Constitucional italiana (de autoría de Virgilio Andrioli, consultable en ww w.cortecostituzionale.it) y el no menos famoso informe de G. Tesauro al caso Factortame I y la correspondiente sentencia del Tribunal de Justicia de las Comunidades Europeas (Caso C-213/899, consultable en http://eur-lex.europa.eu/LexUriServ/LexUriServ.do?uri=CELEX:61989 C0213:IT:HTML). Sobre el tema, cfr. Tommaseo, II fondamento costituzionale delta tutela cautelare, en cipriani (al cuidado de), Slalo di dirilto e garanzie processuali. Alli delle II Giornate inlernazionali di diriltoprocessuale civile, ESI, Napoli, 2008, p. 164 y ss.

2 En esos términos se expresa Barona Villar, Medidas cautelares en el arbitraje, ThomsonCivitas, Madrid, 2006, p. 69.

3 Esa parece ser la opinión de Fernandez Rozas, Arbitraje y justicia cautelar, en Revista de la

Corte Española de Arbitraje, Vol. XXII, 2007, p. 24, que inicia justamente su ensayo evidenciando que "la tutela judicial no es tal, sin medidas cautelares adecuadas que aseguren el efectivo cumplimiento de la resolución definitiva recaída en la controversia judicial. Puede afirmarse que su adopción constituye un verdadero derecho fundamental del justiciable tanto en el proceso judicial como en el arbitral".

4 Asi en Situación cautelable, verosimilitud y «periculum in mora», en Direclum. Revista de De-

recho y Política, Año II, N², dic. 2001, p. 65 (hoy en Problemas del proceso civil. El Jurista, Lima, 2003, p. 669). 
Sin embargo hoy, debo reconocerlo, ya no me atrevería a dar una respuesta tan tajante. Es más, hoy tengo la convicción exactamente contraria, en cuanto me parece ya indudable que todo pronunciamiento sobre una instancia cautelar inevitablemente conlleva un "adelanto de opinión" que debería implicar la automática inhabilitación ese juez para conocer y resolver la controversia de fondo por ausencia de lo que el Tribunal Europeo de Derechos Humanos - correcta o incorrectamente- ha llamado "imparcialidad objetiva".

De allí que este trabajo esté enderezado a cuestionar el principio sobre el que se monta toda nuestra legislación procesal -llamémosla así- "no penal" y que tiene su (dramático) correlato en el arbitraje: que el juzgador del fondo de la controversia tiene que ser, como regla, el que conozca del cautelar y sustentar la tesis opuesta: $e l$ juez (persona física) del cautelar no puede ser el mismo que conoce (o conocerá) del proceso enderezado a resolver la controversia de fondo, pues solo así se podrá preservar la imparcialidad (Ilamémosla por ahora así) "objetiva" del juzgador y, como consecuencia, la efectividad misma de la tutela cautelar.

Para ello, confrontaré primero la solución consagrada en el art. 47 de la Ley de Arbitraje del 2008 con los diversos modelos existentes a nivel de la legislación comparada en materia de tutela cautelar arbitral, a fin de verificar si realmente nos hemos "ajustado a los estándares internacionales" (que es lo que se sostiene en la Exposición de Motivos del Decreto Legislativo 1071); luego, pasaré revista a las posiciones asumidas por la doctrina y la jurisprudencia (en particular europea) sobre la compatibilidad entre el principio de imparcialidad y la acumulación en un mismo juez de las funciones cautelares y de resolución del fondo, con las correspondientes repercusiones que ello debería tener en el ámbito arbitral, para, finalmente, esbozar una posible solución frente a la incompatibilidad planteada.

\section{H. POTESTAD CAUTELAR Y ARBITRAJE}

\subsection{La tutela cautelar en Lev de Arbitraje de 2008 v su (supuesto) "ajuste" a los "estándares internacionales"}

Conforme se lee en la Exposición de Motivos de la Ley de Arbitraje (LA) promulgada por Decreto Legislativo $\mathrm{N}^{\circ} 1071$ del 28 de junio de $2008^{5}$, su objetivo era ajustar la ley en ese momento vigente (la Ley 26572 de 1996) "a los últimos avances en la experiencia internacional y a los estándares comúnmente aceptados, haciendo que las características de nuestra ley sean reconocibles y comprensibles para los inversionistas y comerciantes nacionales y extranjeros, de manera que se genere confianza de que en el Perú se arbitra siguiendo las reglas y principios intemacionalmente aceptados". En suma con la nueva ley se trataría que "inversionistas y comerciantes" no peruanos se sientan "como en casa".

La pregunta es si también en materia cautelar la nueva ley se ha ajustado a los "estándares comúnmente aceptados" más allá de nuestras fronteras. 
Veamos.

La LA dedica tres disposiciones a la materia cautelar. La primera en el art. 8.2; la segunda en el art. 47 y la tercera en el art. 48. Me interesan solo las dos primeras disposiciones, pues el art. 48 se refiere a la ejecución de las medidas cautelares arbitrales, que poco tiene que ver con el tema de presente trabajo.

El art. 8.2 LA (bajo la elocuente sumilla "competencia en la colaboración y control judicial) determina quién es el juez competente para la adopción de medidas cautelares: "el juez subespecializado en lo comercial" o en su defecto, el juez especializado en lo civil del lugar en que la medida deba ser ejecutada o el del lugar donde las medidas deban producir sus eficacia" ${ }^{\prime 7}$.

Prima facie, el artículo $8.2^{\circ}$ LA al establecer quién es el juez competente para "adoptar" medidas cautelares parece atribuirle a los órganos judiciales estatales la potestad cautelar aún cuando medie un convenio arbitral o un arbitraje en curso (lo que, como se verá, es efectivamente, el estándar "comúnmente" aceptado más allá de nuestras fronteras).

Sin embargo, esta apariencia se despeja con la lectura del artículo $47^{\circ} \mathrm{LA}$, en particular en su numerales 4 y 5 , que dejan muy en claro que cuando media un convenio arbitral $^{8}$ las potestades cautelares de los jueces estatales está circunscrita temporalmente, esto es solo la tienen hasta "antes de la constitución del tribunal arbitral $^{\prime \prime}$, tanto es así que. una vez constituido, la autoridad judicial debe, bajo responsabilidad (i!), remitir el expediente "en el estado en que se encuentre, sin perjuicio de que cualquiera de las partes pueda presentar al tribunal arbitral copia de los actuados del proceso cautelar". En tal caso, incluso si la autoridad judicial se demora en la remisión del "proceso cautelar", el tribunal arbitral podrá pronunciarse "sobre la medida cautelar solicitada, dictada o impugnada" (!).

Ergo, el tribunal arbitral, una vez constituido, tiene, con absoluta exclusividad, la potestad cautelar en relación a la controversia sometida a su conocimiento.

Naturalmente esto vale solo para el arbitraje doméstico, por cuanto, conforme lo dispone el inc. 9 del artículo $47^{\circ} \mathrm{LA}$, tratándose de un arbitraje internacional, las partes durante el transcurso de las actuaciones arbitrales "pueden también solicitar

$6 \quad$ La LA (que es una ley) parece partir de la premisa en el Perú existen unos jueces "subespecia-

lizados en lo comercial". Tal "subespecialidad" no es legítima, pues ha sido creada por mera resolución administrativa del Consejo Ejecutivo del Poder Judicial, contraviniéndose flagrantemente tanto el art. 106 ("Mediante leyes orgánicas se regulan la estructura y el funcionamiento de las entidades del Estado previstas en la Constitución..."(corno el art. 143 ("Los órganos jurisdiccionales son: la Corte Suprema de Justicia y las demás cortes y juzgados que determine su ley orgánica"). Por tanto, mal ha hecho la LA en legitimar (legislativamente) a tales (inconstitucionales) juzgados.

Respecto de las medidas cautelares judiciales que deban ser acordadas o ejecutadas en el extranjero, v. la nota 10 .

$8 \quad \mathrm{O}$, cuando media uno de esos arbitrajes que vienen impuestos ex lege, como en materia de con trataciones y adquisiciones del Estado.

$9 \quad$ Bien vale reproducir el inciso 4 del art. 47 LA: "Las medidas cautelares solicitadas a una autori dad judicial antes de la constitución del tribunal arbitral no son incompatibles con el arbitraje ni consideradas como una renuncia a él". Esta disposición es una versión "adaptada" del art. 9 de la Ley Modelo de la CNUDMI sobre Arbitraje Comercial Internacional que establece "No será incompatible con un acuerdo de arbitraje que una parte, ya sea con anterioridad a las actuaciones arbitrales o durante su transcurso, solicite de un tribunal la adopción de medidas cautelares ni que el tribunal conceda esas medidas". 
a la autoridad judicial competente, previa autorización del tribunal arbitral (i!), la adopción de las medidas cautelares que estimen convenientes" 10 .

Ello significa que la nueva LA, al igual que su predecesora" - pese a que, según se expresa en su Exposición de Motivos, "la mayoría de los cambios de la norma se deben al tránsito de una ley dualista a una ley monista, que regirá tanto para el arbitraje internacional como para el arbitraje nacional"12- ha dado un trato diferenciado al arbitraje doméstico frente al arbitraje internacional, pues mientras en el primero los jueces estatales solo cuentan con potestad cautelar hasta que se constituya el tribunal arbitral, en el segundo, pendiente el arbitraje, los jueces estatales (no necesariamente peruanos) tienen un poder cautelar concurrente con el de los árbitros. Sin dejar de decir que solo en el caso del arbitraje doméstico el tribunal arbitral tiene vis atrattiva sobre las medidas cautelares judiciales (solicitadas, concedidas o impugnadas, míen-

10 Según Cantuarias Salaverry, Algunos cortos apuntes acerca de la nueva ley de arbitraje

peruana, en Justicia y Derecho, N" 3, enero 2009, nota 9 (http://www.iusticiavderecho.org/revista3/index. $\underline{\mathrm{htm}}$ ). esta salvedad tiene la "finalidad de que, si la parte interesada considera que la decisión judicial peruana podrá ser más fácilmente ejecutada en un tercer Estado que una decisión de un tribunal arbitral, pueda acudir a esa vía". La explicación poco explica, pues si se está ante un arbitraje internacional (en los términos del art. 5 LA) no creo que el juez nacional tenga, como regla, "competencia jurisdiccional" (uso la palabra en el sentido que le da el Libro $X$ del Código Civil) para adoptar medidas cautelares, sino más bien la tendrá, justamente, aquél de un "tercer Estado", por lo que será de aplicación la última parte del art. 8.2, que establece que "Cuando la medida cautelar deba adoptarse o ejecutarse en el extranjero se estará a los tratados sobre ejecución de medidas cautelares en el extranjero o a la legislación nacional aplicable". El tema de la ejecución de resoluciones cautelares peruanas en el extranjero es harto complicado, pues, salvo que entre en juego la Convención Interamericana sobre cumplimiento de medidas cautelares, es bastante difícil que una medida cautelar peruana pueda ser ejecutada sin pasar por el procedimiento de exequátur (previsto para las sentencias), de resultado incierto, pues dudo que una resolución cautelar peruana (dictada siempre inaudita altera parte) pueda ser reconocida. Baste pensar que, en el espacio europeo, el Tribunal de Justicia de las Comunidades Europeas, ha interpretado que es una exigencia para obtener el reconocimiento y ejecución de una resolución cautelar o provisoria dictada en un Estado miembro por parte de otro Estado miembro en base al Convenio de Bruselas ( $y$ ahora del Reglamento $\mathrm{N}^{\circ} 44 / 2001$ del 22 de diciembre 2000), el que la resolución se haya dictado previo contradictorio efectivo con la contraparte (sobre el punto, cfr. Merlin, Le misureprovvisorie e cautelan nelie spazio giudizario europeo, en Rivista di dirilto processuale, 2002, p. 758 y ss; igualmente, cfr., en sentido crítico, Querzola, Tutela cautelare e convenzione di Bruxelles nell 'esperienza della Corte di giustizia delle Comunitá europee, en Rivista trimestrale di diritto e procedura civile, 2002, p. 807 y ss.).

11 En la derogada Ley General de Arbitraje (Ley 26572 de 1996), el sistema era el siguiente:

En el arbitraje nacional, las potestades cautelares estaban así atribuidas:

antes de iniciado el procedimiento arbitral (art. 79), la potestad cautelar le era atribuida al Juez Civil (no estaba nada claro en cuyo caso se atribuye potestad cautelar al Juez civil:

ya iniciado el proceso arbitral propiamente dicho (art. 81), la potestad cautelar (ex lege, es decir, sin necesidad de pacto expreso) ve era atribuida exclusivamente a los propios árbitros; y

durante la tramitación del recurso de anulación o de apelación ante el Poder Judicial (art. 82), las potestades cautelares le eran atribuidas al Juez civil.

Es evidente que la LGA de 1996 le atribuía ex lege potestades cautelares a los árbitros, por lo que sólo cuando estos aún no hubieran entrado en funciones (o sea en la fase "pre-arbitral", correspondiente a la tutela cautelar ante causam en los procesos civiles estatales) o cuando éstas hubieran cesado (con la emisión del laudo) y se hubiera planteado apelación (de estar pactado) o recurso de anulación ante los órganos judiciales estatales, pudiera intervenir el órgano judicial estatal.

II. En el arbitraje internacional, en cambio, el art. 100 LGA reproducía el art. 9 de la Ley Modelo de la CNUDMI sobre Arbitraje Comercial Internacional, disponiendo: "No será incompatible con un convenio arbitral que una parte, ya sea con anterioridad a las actuaciones arbítrales o durante su transcurso, solicite a un tribunal la adopción de medidas cautelares provisionales ni que el tribunal conceda esas medidas".

12 Así la Exposición de Motivos, en sus Consideraciones Finales. Cabe anotar que en tal documento se señalan los "principales" artículos de aplicación exclusiva al arbitraje internacional. Sin embargo, no se menciona el art. 47.9 LA.

athina 
tras que en el internacional (salvo la insólita "autorización") no tienen control alguno sobre ellas.

La pregunta es: ¿Este "sistema" responde realmente a los estándares internacionales?

Antes de dar una respuesta al interrogante, es preciso evidenciar que la inspiración del sistema implantado (o mejor, reimplantado) en la LA respecto de la potestad cautelar en el arbitraje doméstico es por demás clara: protegerlo "de intervenciones judiciales innecesarias" (por parte, ciertamente, de los jueces nacionales), reforzando "no solo las facultades de los árbitros en este aspecto" sino también "evitar conflictos entre las medidas dictadas en sede arbitral con las dictadas en sede judicial" (siempre, ciertamente, la nacional) ${ }^{13}$, sin que -estoy más que segura- haya rozado las mentes de los legisladores que el conferirles (rectius, confirmarles y reforzarles) ex lege las potestades cautelares a las mismas personas que deben resolver la controversia de fondo pudiera poner (siquiera mínimamente) en jaque su (sigo llamándola por ahora) "imparcialidad objetiva".

\subsection{Los modelos circulantes en materia de "justicia cautelar arbitral"}

Como dije en la introducción, en la actualidad existe la marcada tendencia "global" a reconocer potestad cautelar a los árbitros. Se trata de un proceso en curso (en esa línea nosotros hemos sido unos "pioneros"), impulsado fundamentalmente (pero no solo) por la Comisión de Naciones Unidas para el Derecho Mercantil Internacional (CNUDMI), impulso que ha sido plasmado en las enmiendas introducida en el 2006 a la Ley Modelo sobre el Arbitraje Comercial Internacional, específicamente en su (largo) artículo $17^{014}$. La idea de fondo es evitar inoportunas "injerencias" de los órganos judiciales que puedan llegar a comprometer el buen éxito del arbitraje ${ }^{15}$.

13 Todas las frases entrecomilladas pertenecen a la Exposición de Motivos de la LA, al explicitar cuales han sido "los elementos o principios que inspiraron [la] reforma".

14 Sobre las reformas cfr. Sequeiros, La CNUDMI modifica su Ley Modelo sobre arbitraje comercial internacional, en Revista de Derecho Privado. Nueva Época, año VII, No 21 -22, Sept. 2008-abril 2009. p. 125 y ss.

15 Señala Pozzi, Arbítralo e tutela cautelare: profiii comparatistici, en Rivista dell'arbítralo, 2005, p. 17 y ss " que "las razones aducidas como fundamento de la jurisdicción (sic) camelar arbitra son variadas y bastante conocidas. Entre ellas recordamos la oportunidad de no disociar la cognición sumaria y urgente de aquella de fondo, con la finalidad de preservar la unidad del juicio arbitral y su autonomía según razonables cánones de economía procesal. En la hipótesis de un arbitraje internacional, además, la necesidad de instar a la autoridad judicial solo con finalidades cautelares puede implicar dificultades. En primer lugar, el involucrar incidentalmente a un juez que ignora el asunto, quizá en un país extranjero, cuyo idioma y cuyo derecho procesal sean poco familiares a una de las partes, arriesga aumentar los costos y disminuir la oportunidad de la tutela, comprometiendo su efectividad. La misma demanda cautelar podría además resultar dilatoria, constriñendo, por ejemplo, a la contraparte a una anticipada disclusure para resistir a la instancia. Sin contar que, con la sola finalidad de preservar la efectividad de la tutela de fondo, las partes deberían renunciar a las ventajas que notoriamente acompañan al arbitraje (tales como la flexibilidad, la rapidez y la reserva) y que han. en cambio, claramente indicado preferir en la elección del método de resolución de la litis alternativo al juicio. $\mathrm{Ni}$, por último, se puede descuidar que el pronunciamiento en vía urgente y provisional de una resolución anticipatoria podría de hecho vaciar de significado la sucesiva tutela de fondo, alterando sin remedio los equilibrios entre los litigantes y perjudicando - por fuera del procedimiento arbitral - el resultado de la controversia". 
Al estado de la situación, es posible encontrar los siguientes modelos ${ }^{16}$ :

a) El modelo conflictual ${ }^{1}$, en virtud del cual se atribuye la potestad cautelar exclusivamente sólo a los jueces estatales ${ }^{18}$ o sólo a los árbitros ${ }^{19}$;

b) El cooperativo-concurrente, en virtud del cual los árbitros y los jueces nacionales poseen ambos potestad cautelar ${ }^{20}$.

16 Sigo, en esto, el interesante ensayo de Pozzi, Arbítralo e tutela cautelare: profili comparatistici,

cit.. p. 25 y ss. , así como la buena tesis doctoral de Lapiedra Alcami, La inlen'ención judicial en Ia adopción de medidas cautelares en el arbitraje comercial internacional, Universitat de Valencia. Servei de Publicacions, Valencia, 2003 (consultable en http://www.tdx.cesca.eS/TDX-0520104-133924/l.

17 Es llamado "conflictual" por cuanto "toda intervención judicial, aunque urgente, es considerada una indebida intromisión en la esfera de autonomía de las partes y, viceversa, toda medida arbitral una usurpación de las prerrogativas estatales": así Pozzi, ob. cit., p. 25 y s.

18 Esa era la solución tradicional a nivel europeo hasta las últimas reformas y que mantienen Italia y Suiza, esta última, respecto del arbitraje doméstico. Así el art. 818 del CPC italiano establece que: "Los árbitros no pueden conceder secuestros, ni otras medidas cautelares, salvo distinta disposición de ley". En Suiza, los diversos códigos procesales civiles cantonales le otorgan la potestad cautelar solo a los jueces. En el Concordato sobre el arbitraje celebrado del 27 de marzo de 1969 entre algunos cantones suizos (no todos), en su art. 26 se establece que. "Las medidas provisionales son de exclusiva competencia de las autoridades judiciales ordinarias", sin perjuicio de que las partes "puedan espontáneamente someterse a las medidas provisionales propuestas por el tribunal arbitral".

19 Tal era la tendencia de la judicatura estadounidense hasta hace unos años, según la cual bastaba la existencia de una convención de arbitraje para excluir cualquier intervención judicial sobre la controversia. Tal es aún es la solución colombiana, cuya ley le da todo el poder a los árbitros, pero deja desguarnecida a la parte antes del inicio del arbitraje. Tal igualmente parece ser (aunque hay muchas dudas al respecto) el sistema del Convenio sobre arreglo de diferencias relativas a inversiones entre Estados y nacionales de otros Estados-CIADI (Convenio de Washington), cuyo art. 26 al señalar que "Salvo estipulación en contrario, el consentimiento de las partes a procedimiento de arbitraje conforme a este Convenio se considerará como consentimiento a dicho arbitraje con exclusión de cualquier otro recurso". Sin embargo, el art. 39 inc. 6 (introducido en el año 1984) de Reglamento que contiene las Reglas de Arbitraje señala que "Nada de esta regla impedirá que las partes, siempre que lo hayan estipulado en el convenio que registre su consentimiento, soliciten a cualquier autoridad judicial o de otra naturaleza que dicte medidas provisionales, antes o después de incoado el procedimiento, para la preservación de sus respectivos derechos o intereses". Sobre los problemas suscitados por la adopción de medidas cautelares por jueces estatales en relación a los arbitrajes-CIADI, v. BERGAMINI, La tutela cautelare negli arbitrad ICSID, en Rivisla dell 'arbitrato, 2002, p. 413 y ss., en particular respecto del interesante caso Atlantic Tritón c/Guinea, en el que, pese a que existía un sometimiento de las partes al arbitraje-CIADI, la sociedad Atlantic Tritón pidió (y obtuvo) unas medidas de secuestro en Francia. La Corte de Casación francesa, contrariamente a lo considerado por la Corte de Apelación (que había anulado los secuestros), por sentencia de 1986, estableció que nada excluía la intervención de los jueces estatales aunque medie una convención arbitral bajo las reglas CIADI, por lo que casó la resolución de la Corte de Apelación (v. el estudio cit., especialmente p. 430-431).

20 Tal es la solución recomendada por la Ley Modelo de la CNUDM1 (desde su texto original de 1985) y es que seguida por caso todos los ordenamientos que han recientemente renovado su legislación arbitral. Así, la Ley federal suiza de derecho internacional privado de 1989, para el caso del arbitraje internacional ha conf erido poder a los árbitros para dictar medidas provisionales, sin que ello obste al acceso al órgano judicial estatal (sobre el arbitraje internacional suizo: Walter, 1 . 'arbitrato inlernazionale in Svizzera, en Rivisla trimestrale di dirilto e procedura civile, 1989, p.517 y ss.); en la misma línea se mueve el ordenamiento alemán, que con su reforma de 1998, a la par que en el $\S 1033$ ZPO establece que "Un convenio arbitral no excluye que un tribunal jurisdiccional, antes o después del comienzo del arbitraje, pueda ordenar a instancia de una parte medidas provisionales o de aseguramiento respecto a la cuestión objeto de arbitraje", en el § 1041.1 establece que "Si las partes no hubieran acordado algo distinto, el tribunal arbitral podrá ordenar a instancia de parte medidas provisionales o de aseguramiento, que resulten convenientes respecto del objeto del litigio" (sobre el arbitraje alemán: Von Schlabrendorff, Régimen jurídico del arbitraje en Alemania, en Anuario de Justicia Alternativa, $\mathrm{N}^{\circ} 4$, 2003, p. 117 y ss., especialmente p. 128); en España, el art. 11.3 de la Ley 60/2003, de Arbitraje, establece también que "El convenio arbitral no impedirá a ninguna de las partes, con anterioridad a las actuaciones arbitrales o durante su tramitación, solicitar de un tribunal la adopción de medidas cautelares ni a éste concederlas". En la reciente reforma austríaca del año 2006, conforme al § 585 de la ZPO las partes que pretendan valerse de la tutela cautelar pueden dirigirse tanto a los árbitros como al juez estatal (sobre este aspecto de las reforma, cfr. Aschauer, II nuovo dirilto dell'arbitrato austríaco, en Rivisla dell arbitrato, 2006, p. 249 y ss.). Y así se podría seguir. 
c) El cooperativo-subsidiario, en virtud del cual son los árbitros los que tienen en preminencia la potestad cautelar, salvo que éstos no puedan actuar eficazmente, en cuyo caso, puede entrar en subsidio la autoridad judicial ${ }^{21}$.

El modelo imperante, sin embargo, es el cooperativo-concurrente, que es, por cierto, el recomendado por la CNUDMI. Cabe aclarar que en la Ley Modelo de la CNUDMI ( $y$ en buena parte de los ordenamientos nacionales que le han conferido potestades cautelares a los árbitros) las partes no solo pueden acudir a su elección a los árbitros o a los jueces estatales ${ }^{22}$, sino que además pueden pactar expresamente en su convención arbitral que los árbitros no tengan potestad cautelar alguna ${ }^{23}$, por lo que en buena cuenta, está en su disponibilidad también la posibilidad de darle o no unos poderes que pueden Ilegar a comprometer la (Ilamada) "imparcialidad objetiva" de quienes deberán resolver su controversia.

\subsection{Conclusión: nuestra LA no se ajusta a los "estándares internacionales"}

Es evidente pues que nuestra LA, por lo que atañe al arbitraje doméstico, está más cercana a un modelo conflictual que al modelo recomendado por la CNUDMI, mientras que respecto del arbitraje internacional se acerca un tanto, pero sin prever el pacto derogatorio de las potestades cautelares arbitrales y exigiendo de las partes (sin saberse, por cierto, a cuál consecuencia se enfrenten si no lo hacen) que decidan acudir a los órganos judiciales estatales la "previa autorización del tribunal arbitral".

Ergo, habría que concluir que definitivamente nuestro arbitraje doméstico, en cuanto a lo cautelar, no está para nada cercano a los "estándares internacionales" 24, con la consecuencia de que "sí o sí" todo aquel que por pacto (o, peor, por ley...) debe resolver una controversia a través del arbitraje, una vez "instalado el tribunal arbitral" no tendrá más camino que intentar obtener tutela cautelar de aquellas mismas personas que deberán resolver el fondo de la controversia, es decir, que (repito) "sí o sí" las mismas personas físicas encargadas de resolver la controversia deberán pronunciarse sobre las instancias cautelares.

21 Modelo seguido por art. 44.5 de la Arbitration Act inglesa de 1996 que establece que "los jueces

solo actuarán cuando el tribunal arbitral no tenga poder para hacerlo o sea incapaz de actuar de forma eficaz" y, en parte, por el Reglamento de Arbitraje de la de la Cámara de Comercio Internacional (ICC), que en su art. 23.2 establece: "Las partes podrán, antes de la entrega del expediente al Tribunal Arbitral y en circunstancias apropiadas aún después, solicitar a cualquier autoridadjudicial competente la adopción de medidas provisionales o cautelares. La solicitud que una parte haga a una autoridad judicial con el fin de obtener tales medidas o la ejecución de medidas similares ordenadas por un Tribunal Arbitral no contraviene al acuerdo de arbitraje ni constituye una renuncia a éste y no afecta los poderes del Tribunal Arbitral al respecto. Dicha solicitud, así como cualquier medida adoptada por la autoridad judicial, debe ser notificada sin dilación a la Secretaría. Esta última informará de ello al Tribunal Arbitral" (evidenciado mío).

22 Señala el art. 17-J de la Ley Modelo de la CNUDMI que "El tribunal (se refiere al estatal) gozará de la misma competencia para dictar medidas cautelares al servicio de actuaciones arbitrales, con independencia de que éstas se sustancien o no en el país de su jurisdicción, que la que disfruta al servicio de actuaciones arbitrales. El tribunal ejercerá dicha competencia de conformidad con sus propios procedimientos y teniendo en cuenta los rasgos distintivos de un arbitraje internacional".

23 Así señala el inciso 1) del art. 17 de la Ley Modelo de la CNUDMI que "Salvo acuerdo en contrario de las partes, el tribunal arbitral podrá, a instancia de una de ellas, otorgar medidas cautelares". Igual manera (y eso sí es lo máximo) en el Convenio-CIADI, en su art. 46 expresamente señala que "Salvo acuerdo en contrario de las partes, el Tribunal, si considera que las circunstancias así lo requieren, podrá recomendar la adopción de aquellas medidas provisionales que considere necesarias para salvaguardar los respectivos derechos de las partes".

24 Como se señala en las Consideraciones Finales de su Exposición de Motivos. 
Pero hay un detalle importante, muy apreciable en la Ley Modelo de la CNUDMI, que no quiero dejar de mencionar: en el artículo $17-\mathrm{A}^{\circ}$, bajo la sumilla "condiciones para el otorgamiento de medidas cautelares" se prescribe:

"1) El solicitante de alguna medida cautelar prevista en los apartados a), b) o c) del párrafo 2 ) del artículo $17^{\circ}$ deberá convencer al tribunal arbitral de que:

a) De no otorgarse la medida cautelar es probable que se produzca algún daño, no resarcible adecuadamente mediante una indemnización, que sea notablemente más grave que el que pueda sufrir la parte afectada por la medida, caso de ser ésta otorgada; $y$

b) Existe una posibilidad razonable de que su demanda sobre el fondo del litigio prospere. La determinación del tribunai arbitral respecto de dicha posibilidad no prejuzgará en modo alguno toda determinación subsiguiente a que pueda llegar dicho tribuna!.

2) En lo que respecta a toda solicitud de una medida cautelar presentada con arreglo al apartado d) del párrafo 2) del artículo $17^{\circ}$, los requisitos enunciados en los apartados a) y b) del párrafo 1) del presente artículo sólo serán aplicables en la medida en que el tribunal arbitral lo estime oportuno"25.

La disposición es, sin duda, interesante porque deja traslucir que a los técnicos de la CNUDMI sí les rozó por la mente el (evidente) problema del riesgo de pérdida de "imparcialidad objetiva" de los árbitros y trataron de resolverlo desplazando el baricentro del fumus al periculum, a valorarse según el conocido criterio (o test) anglosajón del "balance de conveniencia" 26 , dejando así para después el análisis de la "posibilidad razonable" de que la demanda (de fondo) prospere, con advertencia (nótese) de que tal determinación "noprejuzgará en modo alguno toda determinación subsiguiente a que pueda llegar dicho tribuna!".

Lo curioso es que nuestra LA (en su art. 47.2), pese a haber tomado (casi) al pie de la letra del artículo $17^{\circ}$ de la Ley Modelo de CNUDMI (en la versión reforma-

\footnotetext{
25 Cursivas mías.

26 El tradicional criterio anglosajón del "balance de conveniencia", fue reelaborado por Lord Diplock, juez de la House of Lord, en la famosa sentencia del caso American Cyanamid v. Ethicon Lid de 1975. Tal sentencia marca un viraje en cuanto a los presupuestos para la concesión de una interloculory injunction pues si antes se exigía la evaluación por parte del juez de: a) la solidez de los argumentos del demandante (the strength of the piantiff $s$ case) y b) la naturaleza y extensión del daño (harm) de cada parte, con la opinión de Lord Diplock, se varía el primer requisito, que debería reducirse a la simple constatación de que detrás de la solicitud de una medida cautelar hubiera una cuestión "seria" que enjuiciar serious question to be iried) y solo una vez sentado que no se trata de una cuestión "frívola", deberá quedar demostrado que el balance de conveniencia favorece la concesión de la medida provisional. Sobre el tema, VARANO, Tendenze evolulive in materia di tutela promisoria nell ordinamento inglese con parlicolare riferimento ali'interlocutory injunction, en Rivista di dirilto civile, 1985, I, p. 45 y ss., asi como Marín González, REFERENCIA A LA TUTELA CA UTELAR EN EL DERECHO INGLÉS, en Revista de Derecho (Valdivia), Vol. XV, diciembre 2003, p. 191 y ss.
} 
da en el 2006) $)^{27}$ tanto la noción de medidas cautelares como sus posibles contenidos, no haya también adoptado su artículo $17-\mathrm{A}^{\circ}$, que, como dicho, inviniendo los términos "usuales" del análisis de una solicitud de tutela cautelar (es decir, primero el periculum, luego el fumas) ha pretendido ahuyentar el fantasma del prejuzgamiento, que es lo que hace - según lo confiesan algunos árbitros- que no sea para nada usual que los tribunales arbitrales adopten medidas cautelares, justamente para no dar la impresión a las partes "que han prejuzgado el fondo del asunto"28.

\section{En efecto, el artículo 47.2 LA es copia casi textual de la Ley Modelo de la CNUDMI (quizá}

las diferencias entre el texto de la LA y la versión en español de la Ley Modelo, se deba a que fue tomada y traducida del texto en inglés). Probablemente los autores de la LA no se dieron cuenta de que todas las medidas cautelares allí previstas están montadas sobre el modelo de las injunction anglosajonas, que son remedios in personam (y no reales), que consisten justamente en ordenes de hacer o de no hacer, que no son susceptibles de ejecución forzada y que la única forma para asegurar que su destinatario las cumpla (si es que son dispuestas por un órgano judicial) es la amenaza del contempt of court, es decir, a través de medidas coercitivas. De allí la antinomia existente en el artículo $48^{\circ}$ LA que en su inc. I establece que "El tribunal esta facultado para ejecutar, a pedido de parte, sus medidas cautelares" (¿cómo se "ejecuta" una orden dirigida a hacer o dejar de hacer dirigida a la parte?), agregando que "a su sola discreción" podra "requerir la asistencia de la fuerza pública " (¿podrá acaso disponer el arresto de la parte desobediente hasta que cumpla, tal como lo hacen los jueces - no ciertamente los árbitros-anglosajones?). Más incomprensible aún es la previsión del inc. 2 del artículo $48^{\circ}$ LA que establece que en los casos de incumplimiento de la medida cautelar o cuando requiera de ejecución judicial (¿cuándo?), la parte interesada recurrirá a la autoridad judicial competente". Con ello queda demostrado que al copiar la Ley Modelo de la CNUDMI los autores de la LA no entendieron que se le estaba dando a los árbitros solo el poder de disponer medidas cautelares in personam y no in rem, por lo que, por ejemplo, no podrían disponer el embargo o el secuestro de bienes, sino solo que se "proporcione algún medio para preservar los bienes que permitan ejecutar el laudo" (art. 47.2.c). En suma, no se dieron cuenta que las únicas medidas cautelares posibles son ordenes dirigidas a las partes y solo a las partes, por lo que jamás podrían ordenar nada a un tercero (mucho menos a una autoridad), cosa que todos los que conocen (o deberían conocer) de la experiencia cautelar arbitral tienen conciencia. Al respecto señala Pozzi, Arbitrato e tutela cautelare, cit.. p. 28 que "es pacífico que ninguna medida puede ser dispuesta por los árbitros en relación a quienes no estén sujetos a la eficacia del acuerdo compromisorio. Un caso ejemplar está representado por las garantías bancarias a primer requerimiento: la convención arbitral contenida en el contrato principal entre ordenante y beneficiario de la garantía puede, en efecto, desembocar, en perspectiva cautelar, en una resolución que inhibe la excusión amenazada por el beneficiario en contra del ordenante. Tal inhibitoria será vinculante inter partes pero no en relación al banco que ha prestado la garantía por cuenta de ordenante, de forma que el pago de la garantía al beneficiario a despecho de la resolución cautelar encontrará difícilmente adecuada sanción". En similar sentido, Lapiedra Alcami, La intervención judicial en la adopción de medidas cautelares en el arbitraje comercial internacional, cit.. p. 262 y ss., para quien derivando el poder de los árbitros de la cláusula arbitral, "un árbitro nunca podrá adoptar una medida cautelar imponiendo una obligación a un tercero ajeno a dicho acuerdo de sumisión (...). Dicho de otro modo, el poder de los árbitros es limitado ratione personae".

28 Así lo señala Silva Romero, Adopción de medidas cautelares por el juez y por el árbitro, ponencia en el "II Congreso Internacional del Club Español de Arbitraje-El Arbitraje y la Jurisdicción (Madrid 17-19 de junio de 2007)", en http://www.clubarbitraje.com/files/docs/Adopcion de Medidas Cautelares por el

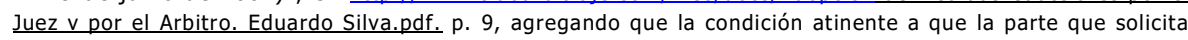
la medida cautelar deba demostrar cierta probabilidad de éxito en cuanto al fondo del asunto, "[d]e conformidad con nuestra experiencia en la CCI, [...] es quizá la condición que hace que los árbitros sean muy reticentes a la hora de adoptar medidas cautelares. Muchos árbitros sienten que, de hacerlo, le estarán trasmitiendo a las partes la idea que ya han prejuzgado el caso y tomado su decisión en cuanto al fondo del asunto" (p. 14). Lo refiere también Fernandez Rozas, Arbitraje y justicia cautelar, cit.. p. 32, al señalar que la apreciación del fumus boni iuris "no siempre es fácil pues siempre se corre el riesgo de que se adelante un pronunciamiento que puede repercutir sobre el fondo del asunto en el procedimiento principal y que el juez o el árbitro se contamine para pronunciarse acerca de esta última cuestión". En el ámbito de los arbitrajes-CIADI, en donde, por cierto, el tribunal arbitral no puede sino emitir "recomendaciones" cautelares, según lo refiere Bergamini, La tutela cautelare negli arbitrad ICSID, cit., p. 436, "todas las medidas concedidas tuvieron un carácter y una función estricta y exclusivamente inhibitoria: dato indiscutible es que nunca fue dispuesta ninguna medida de naturaleza conservativa". 
Con esta omisión, resulta evidente que, en especial para el arbitraje doméstico, los autores de nuestra LA estaban más preocupados por evitar "intervenciones judiciales innecesarias" que por la enojosa situación en la que se puede terminar colocando a las partes, privadas de poder acceder a la los órganos judiciales estatales y con árbitros renuentes hacia la tutela cautelar para no dar "malas" impresiones a las mismas partes...

\subsection{Las medidas cautelares "pre arbitrales"}

A nivel de algunas grandes y prestigiosas instituciones que manejan arbitrajes internaciones se han "inventado" unas soluciones "alternativas" para la tutela cautelar, consistentes en la introducción de procedimientos "pre-arbitrales" (a cargo de los llamados "árbitros de emergencia"), enderezados a la emisión de medidas provisionales, en particular en la espera de la constitución del tribunal arbitral (que como se sabe puede durar mucho tiempo) $)^{29}$.

A los fines de este trabajo me interesa evidenciar una: el "référépré-arbitraT" de la Cámara de Comercio Internacional (traducida por la propia CCI al español como "procedimiento precautorio prearbitral"), que se encuentra regulado en un Reglamento entrado en vigor el 1 de enero de $1990^{10}$.

La propia CCI presenta así su procedimiento "alternativo":

"Un gran número de contratos, particularmente aquellos que tienen por objeto operaciones a largo plazo, pueden dar lugar a problemas que requieran una respuesta urgente. Frecuentemente, no es posible obtener en el tiempo requerido una decisión definitiva de un tribunal arbitral o de un juez.

En consecuencia, la Cámara de Comercio Internacional (CCI) ha establecido el presente Reglamento instituyendo un procedimiento precautorio pre arbitral con el fin de permitir a las partes que así lo hayan convenido, recurrir rápidamente a una persona (Ilamado el Tercero) facultada para ordenar medidas tendentes a resolver un problema urgente, incluyendo mantener o conservar pruebas. Las medidas precautorias ordenadas, por tanto, podrán proveer una solución provisional de la disputa y podría sentar las bases para su solución definitiva ya sea mediante acuerdo o de alguna otra forma.

La utilización del procedimiento precautorio pre arbitral no sustituye la jurisdicción arbitral o estatal competente para decidir sobre el fondo de cualquier desavenencia subyacente".

Conforme al artículo $2.1^{\circ}$ del Reglamento, el "tercero" puede dictar (previo contradictorio entre las partes, como es propio del procedimiento de référé judicial) las siguientes medidas:

29 Una visión detallada sobre las medidas provisionales pre-arbitrales (privadas) puede encon-

trarse en LAPIF.DRA ALCAMI, La intervención judicial en la adopción de medidas cautelares en el arbitraje comercial internacional, cit., p. 294 y ss.

30Sobre este procedimiento se ha escrito mucho, siempre en términos muy elogiosos. Sin embargo. al parecer no ha tenido mucho éxito, pues su aplicación ha sido escasa, en particular porque si las partes no se adecúan a las órdenes de référé, no hay forma de ejecutarlas. Sobre el tema v. Cari.evaris, Tutela cautelare "prearbitrale": natura del procedimento e della decisione, en Rivista dell'arbítralo, 2003. p. 259 y Ss. Igualmente el elogioso ensayo de CORREA DEL CASSO, Arbitraje y refere en Francia. Reflexiones finales en torno a nuestro actual sistema de medidas cautelares en materia arbitral, en Anuario de Justicia Alternativa, N" 9. 2008. p. 153 y ss. 
a) ordenar cualesquiera medidas conservatorias o medidas restitutorias que sean urgentemente necesarias ya sea para evitar el daño inminente o la pérdida irreparable, y así salvaguardar cualquiera de los derechos o bienes de una de las partes;

b) ordenar a una de las partes que efectúe a otra de las partes o a cualquier otra persona, un pago que debiera ser efectuado;

c) ordenar a una de las partes que tome cualquier medida que pudiere ser adoptada de conformidad con el contrato entre las partes, incluyendo la firma o entrega de cualquier documento o la intervención de una de las partes para procurar la firma o entrega de un documento;

d) ordenar cualesquiera medidas que sean necesarias para conservar o constituir pruebas".

Lo más interesante (a los efectos del presente trabajo) está en el art. 2.3 del Reglamento, cuando establece:

"A menos que las partes acuerden lo contrario por escrito, un Tercero nombrado de conformidad con este Reglamento no podrá actuar como árbitro en cualquier procedimiento subsiguiente entre las mismas partes o en cualquier procedimiento en que exista un problema o una cuestión que sea idéntica a o se relacione con cualquiera de las cuestiones que hayan surgido en el procedimiento seguido ante el Tercero".

Ergo, según el Reglamento, el "tercero" que conoce del procedimiento pre arbitral no podrá conocer y resolver el fondo de la controversia, salvo que las partes acuerden (por escrito) lo contrario. Señal que la CCI consideró que con su intervención, el "tercero" dejaba de ser "tercero" a los efectos de la solución de la controversia de fondo. Que es algo que hay que tener muy en cuenta.

\section{IMPARCIALIDAD “OBJETIVA" Y TUTELA CAUTELAR}

\subsection{La Jurisprudencia del TEDH sobre la imparcialidad (llamada)}

"objetiva". Idas v venidas.

La distinción entre la llamada imparcialidad "subjetiva" y la "objetiva" pertenece a la jurisprudencia del Tribunal Europeo de Derechos Humanos ha sido seguida (bastante acríticamente ${ }^{31}$ ) un tanto por todos los Tribunales y Corte Constitucionales europeos y Latinoamericanos ${ }^{32}$, incluso por el nuestro ${ }^{33}$.

Para el Tribunal de Estrasburgo, mientras que la primera "se determina a través del concreto pensamiento del juez, valorando si sus concretos comportamientos o

\footnotetext{
31 Cfr., en cambio, la aguda critica a la jurisprudencia del TEDH de Montero AROCA, La impar-

cialidad judicial en el Convenio Europeo de Derechos Humanos, en Ferrer Mac-Gregor-Zaldivar Lelo de Larrea, La ciencia del derecho procesal constitucional. Estudios en homenaje a Héctor FLx-Zamudio en sus cincuente años como investigador, T. IX, Unam, México, 2008, p. 777 y ss.

32 Respecto al Tribunal Constitucional español, cfr. CAstruo CórDova, El derecho fundamental al juez imparcial: influencias de la jurisprudencia del TEDH sobre el Tribunal Constitucional español, en Anuario de Derecho Constitucional Latinoamericano, 2007, p. 121 y ss.

33 V. sobre todo la STC emitida el 11 de diciembre de 2006. en los expedientes acumulados $\mathrm{N}^{\circ}$ 6149-2006-PA/TC y 6662-2006-PA/TC y, más recientemente, la STC Nº 02851-PA/TC del 15 de marzo de 2011, ambas,
} curiosamente, en materia arbitral. 
las expresiones por él utilizadas puedan evidenciar su efectiva parcialidad, y dada la dificultad de tales determinaciones, se presume hasta prueba en contrario, la segunda presupone simplemente que se encuentren elementos que, sobre la base de consideraciones inherentes a la objetiva posición del juez en el ámbito del órgano al que pertenece o de las funciones por él ejercitadas, puedan hacer aparecer al juez parcial, independientemente de su conducta" ${ }^{34}$.

En tal sentido, el TEDH, con la finalidad de determinar la imparcialidad (llamada) "objetiva" atribuye relevancia también a las meras apariencias (el juez no debe ser solo imparcial, sino que tiene que parecerlo...), y ello particularmente en el caso de acumulación de funciones incompatibles en el mismo juez. En tal sentido el desarrollo por parte de la misma persona de más de una función en diversas fases de un mismo proceso podría legítimamente justificar el temor de la parte interesada de que juez no tenga la capacidad de separarse de la opinión que ya se haya formado sobre el resultado del asunto.

Es así que en el famoso caso Piersak contra Bélgica (del año 1982), la Corte de Estrasburgo consideró que pese a que no había razón alguna para dudar de la capacidad personal del magistrado para decidir de manera imparcial, condenó a Bélgica, reconociendo que no ofrecía suficientes garantías de imparcialidad el juez que tenía que juzgar al acusado, pues éste antes había ocupado la función de fiscal, con la (mera) posibilidad de haber conocido el expediente. De igual manera se resolvió en el caso De Cubber contra Bélgica (de 1984), en donde el TEDH encontró que era incompatible la participación en la fase de juzgamiento de un magistrado que se había desempeñado antes como juez instructor.

En pronunciamientos algo más recientes el TEDH parece haber dado marcha atrás en su "objetivización" de la imparcialidad. Es así que en el caso Hauschildt contra Dinamarca (de 1989), afirmó que los meros temores respecto a la parcialidad del juez no serian de por sí suficientes para determinar la violación del derecho al juez imparcial, sino que tiene que irse caso por caso, verificando si la intervención precedente del magistrado realmente comprometió o no su imparcialidad. En el caso se consideró subsistente la violación del artículo $6.1^{\circ}$ de la Convención de Roma, pero no solo sobre la base de la simple constatación del hecho de que el juez que debía resolver sobre el fondo de la acusaciones había pronunciado antes medidas de detención provisional, sino más bien analizando el concreto ámbito de conocimiento del caso que había tenido precedentemente ese magistrado.

Con ello la imparcialidad "objetiva" de abstracta se volvió "concreta". Y ese será el metro que vendrá aplicado por el TEDH en todos los sucesivos casos ${ }^{35}$.

\subsection{La Corte Constitucional italiana v su distinta "sensibilidad" en el ámbito} penal v en el ámbito civil

Con todo, la imparcialidad "objetiva" (construida, por cierto, conociendo sustancialmente asuntos en materia penal), tal como diseñada originalmente por el TEDH tendrá sus consecuencias en los ordenamientos nacionales. 
Es así que en el año 1996, la Corte Constitucional italiana, tras previos titubeos $^{36}$, pronunció finalmente dos decididas sentencias (la $N^{\circ} 155$, del 20 de mayo; y la $\mathrm{N}^{\circ} 131$, del 24 de abril), en las que declaró la ilegitimidad constitucional del art. 34 del Código de Procedimiento Penal en la parte en la cual no establece la incompatibilidad para participar en el juzgamiento no solo del juez que haya dispuesto una medida cautelar personal así como del que haya participado en el tribunal de reexamen de la medida cautelar misma, sino también en todas las hipótesis en las cuales la imparcialidad de la función pueda resultar perjudicada por la precedente asunción de decisiones, en otra fase del procedimiento, en orden a medidas cautelares personales dispuestas en contra del investigado o del imputado.

En base a estas sentencias, tanto la doctrina más sensible, como muchos jueces, sintieron que este riesgo "objetivo" de pérdida de imparcialidad podía verificarse "de matera análoga y con idénticas consecuencias también en relación al caso en el cual el mismo juez civil, que haya conocido en un momento precedente a la instauración del juicio de fondo o en el curso del mismo el material de la causa a los fines del pronunciamiento de una medida cautelar, sea llamado luego a resolver el fondo"37.

Es así que la Consulta se vio investida de una serie de cuestiones de constitucionalidad, promovidas por jueces civiles, respecto del inc. 4 del artículo $51^{\circ}$ del Código de Procedimiento Civil, en cuanto no preveía entre los motivos de abstención del juez el haber emitido, previamente al conocimiento del fondo, medidas cautelares, sino solo el (tradicional) conocimiento de la causa "en otro grado" del proceso.

Sin embargo, si la Corte Costituzionale se mostró muy sensible en materia penal en la preservación de la imparcialidad "objetiva" del juez (y proteger al procesado penal del riesgo de la "fuerza de la prevención"), no ocurrió lo mismo en el ámbito civil.

Es así que en la Sentencia No 326/1997, declara infundada la cuestión, e invocando la tendencia restrictiva arriba indicada del TEDH, argumentó que "condición necesaria para considerar una incompatibilidad endoprocesal es la preexistencia de valoraciones que recaen sobre la misma res iudicanda, o, más exactamente, es la duplicación de los juicios de la misma naturaleza por el mismo juez", lo que no ocurre en el caso de las medidas cautelares civiles pues la concesión de la medida ante causam se funda en presupuestos del perjuicio irreparable y del fumus boni iuris. Ahora, teniendo en cuenta la ajenidad del primero respecto de la presente cuestión, el segundo debe resultar de una simple valoración probabilística sobre las buenas razones del actor, las cuales están preservadas del riesgo de quedar irreversiblemente comprometidas durante el tiempo necesario para hacerlas valer en vía ordinaria. De aquí su carácter instrumental (respecto -debe subrayarseno al fondo de la causa, sino a la realización del derecho a determinar en esa sede) asumido por la resolución cautelar, y la conexa estructura sumaria de la cognición".

Con ello la Corte Constitucional italiana no hizo sino recoger la communis opinio de que juzgar en el cautelar no implica ningún "prejuzgamiento", por lo que, si el mismo juez-persona física acumula en sí el de ser juez del cautelar y del fondo, sentencias indicadas a continuación en el texto).

Así MoReTti, ob. cit.. p. 1086 y s. El escrito de la Moretti es inmediatamente posterior a la emisión de las sentencias de la Consulta indicadas en el texto. 
no habría incompatibilidad funcional, ni estaría en riesgo —en abstracto- su imparcialidad "objetiva"38.

El argumento, al parecer no convenció a los jueces de fondo, por lo que la Consulta se vio investida nuevamente de otras cuestiones de constitucionalidad prácticamente idénticas a la anterior. Es así que por auto No 193/1998 declaró que la cuestión (siempre respecto del artículo $51^{\circ}$ del Código de Procedimiento Civil) como manifiestamente infundada, reproduciendo los argumentos expresados en la Sentencia No $326 / 1997$.

Un (más aparente que real) revirement de la Consulta, sin embargo, se produjo con la Sentencia 387/1999 (del 11 de octubre de 1999, es decir, cuando estaba en plena discusión en el Parlamento italiano la modificación del art. 111 de la Constitución, con la introducción finalmente en su texto de la "terzietá e imparzialitá" del juez cual componente del debido proceso). En ella nuevamente un juez levanta la cuestión de constitucionalidad el artículo $51^{\circ}$ inc. 4 del CPC italiano. Esta vez, sin embargo, no estaba en juego una resolución calificada por la ley como cautelar, sino de aquella a emitirse en el procedimiento especial de represión de la conducta antisindical (que consiste en la orden de reposición del sindicalista despedido: artículo $28^{\circ}$ del Estatuto de los Trabajadores de 1970). En el caso el juez había declarado infundada la demanda de reposición del trabajador y contra ella se había planteado oposición (que es la segunda fase del procedimiento), cuyo conocimiento le fue asignado al mismo juez. La cuestión fue declarada infundada, pero la sentencia hizo una interpretación "constitucionalmente orientada" del inc. 4 del art. 51 del CPC italiano (la Sentencia $387 / 1999$ es una sentencia interpretativa de desestimación), en el sentido de que la expresión "otro grado del procedimiento" debe entenderse a la luz de los principios que se extraen de la Constitución relativos del debido proceso, como expresión necesaria del derecho a una tutela jurisdiccional mediante acción (artículo $24^{\circ}$ de la Constitución) ante un juez con las garantías propias de la jurisdicción, es decir, con la connatural imparcialidad, sin la cual no tendría significado ni el sometimiento de los jueces a la ley (artículo $101^{\circ}$ de la Constitución), ni la misma autonomía e independencia de la magistratura", por lo que "la expresión «otro grado» no puede tener un ámbito restringido al solo distinto grado del proceso, según el orden de las dependencias judiciales, como previsto por el ordenamiento judicial, sino que debe comprender - con una interpretación conforme a la Constitución - también la fase que, en un proceso civil, se sucede con carácter de autonomía, teniendo contenido impugnatorio, caracterizada (...) por un pronunciamiento que se refiere al mismo objeto y a las mismas valoraciones decisorias sobre el fondo de la acción planteada en la primera fase, aunque ante el mismo órgano judicial".

Ergo, en este caso, la Consulta halló sí que se comprometía la imparcialidad del juez si se le imponía conocer de la fase sumaria y la fase plenaria del procedimien -

38 Según VIGNERA, La garanzia costituzionale delta terzietá del giudice civile, en Informazione

previdenziale, Nov. Dic. 2003, p. 1451 y s., la Corte Constitucional italiana ha estado inspirada exclusivamente por la intención de comprimir al máximo el área de las incompatibilidades del juez civil, sin tomar en cuenta que "presupuesto para la concesión de la medida cautelar es la cognición sumaria (no definitiva, sino "al estado de los autos") del derecho accionado, cuya existencia debe aparecer probable a la luz (no solo de las afirmaciones de la parte instante, sino) de los elementos probatorios ofrecidos por las partes o adquiridos de oficio", por lo que "la valoración del fumus boni iuris en el procedimiento cautelar civil se presenta "cualitativamente correspondiente (o con todo análoga) a la relativa a los «graves indicios de culpabilidad» realizada en el ámbito del procedimiento aplicativo de una medida cautelar persona] (artículo $273^{\circ}$, primer párrafo, CPP)". 
to, pero no declaró la inconstitucionalidad de la disposición cuestionada, pero hizo sí su "interpretación conforme", que en definitiva implica que, en casos como los que motivaron la cuestión de constitucionalidad, el juez (persona física) del procedimiento sumario debe ser distinto del plenario ${ }^{39}$.

Poco después, en noviembre de 1999, sobrevino la reforma del artículo $111^{\circ} \mathrm{de}$ la Constitución, introduciendo que el que "todo proceso se desenvuelve ante un juez tercero e imparcial", lo que reabrió la esperanza de la doctrina más sensible ${ }^{40}$ de que la Corte Constitucional revisara su criterio restrictivo en el campo de la acumulación de funciones. Aún, por lo que sé, se está esperando ${ }^{41}$.

39 la Corte Constitucional italiana $N^{\circ} 460$, del 23 de diciembre de 2005, respecto al juicio de oposición a la sentencia declarativa de quiebra prevista por el (ya reformado) art. 18 de la Ley de Quiebra.

40

En particular, SCARSELLI, Articolo 111 della Costituzione e incompatibilitá de! giudice nel pro ceso civile, fallimentare e minorile, en II nuovo articolo III della Costituzione e il giusto proceso civile, FrancoAngeli, 2001, p. 87 y ss., para quien "habría que preguntarse si las indagaciones sobre el fumus por un lado, o bien las indagaciones sobre los presupuestos de una resolución sumaria decisoria cual el decreto de represión de la conducta antisindical, por la otra, puedan realmente justificar un tratamiento diferenciado en cuanto a la incompatibilidad del juez. Yo creo que no, y creo que quien pretenda sostener aquello, debería probar no sólo que la determinación del fumus en las medidas cautelares es distinto de la determinación que se tiene en la cognición sumaria decisoria, sino también que tal diferencia es tan grave como para considerar en un caso al juez comprometido bajo el perfil de la fuerza de la prevención mientras en el otro no. Las dificultades de una tal demostración me inducen a confirmar la opinión según la cual la incompatibilidad del primer párrafo n. 4 de artículo $51^{\circ} \mathrm{CPC}$ debe reconocerse también en la relación entre medidas cautelares y juicio de fondo; si bien la cuestión, al día de hoy, no ha encontrado consenso ni en la jurisprudencia ni en la doctrina más autorizada, y queda, por tanto en la duda". Decididamente en contra, ChIARLoni, II nuovo articolo III della Costituzione e il processo civile, en II nuovo articolo III della Costituzione e il giusto proceso civile, cit., p. 30 y s., para quien si bien es verdad que entre los presupuestos para la emanación de medidas cautelares se comprende "bajo la tradicional etiqueta del fumus boni iuris, una valoración en orden a la existencia del derecho del que se pide la cautela", "no se trata de una valoración profunda, como la ahora requerida por el legislador del proceso penal para las medidas cautelares personales. Ella es, más bien, extremamente sumaria, al punto que, en las praxis concretas, por lo general se esfuma, frente a la valoración del periculum in mora al que los jueces civiles atribuyen justamente la mayor importancia. Forzando un poco las cosas se podría decir que, una vez determinado el periculum in mora, el juez civil se preocupa del otro requisito inviniendo, por así decirlo la perspectiva, y negará la medida pedida solo si se dé cuenta de que el derecho a cautelar planteado por el actor es en realidad ido oculi inexistente".

41

Si bien en materia cautelar no ha habido cambio alguno, sí lo ha habido en otros ámbitos y no por obra de la Corte Constitucional, sino del legislador. Así, por un lado, al reformarse la Ley de Quiebra (por D.leg. $\mathrm{N}^{\circ} 5$, del 9 enero 2006 y D.Leg. $\mathrm{N}^{\circ}$ 169, del 12 setiembre 2007) se estableció que contra la sentencia de quiebra ya no procede la oposición sino la queja (reclamo) de competencia de la Corte de Apelación (con lo cual se corta por lo sano toda posibilidad de identidad de juez-persona) y, por el otro, por Ley $N^{\circ} 69$, del 18 de junio de 2009, se estableció, en el art. 186-bis de las disposiciones de actuación del CPC italiano, que el juicio de fondo sobre la oposición a los actos ejecutivos debe ser tratado por "un magistrado distinto de aquel que ha conocido de los actos en contra de los cuales es planteada la oposición". Mayores detalles sobre situación actual en FABBiani, Garanzia di terzietá e imparzialitá del giudice ed ejfi-

cienza del proceso, en www.iudicium.it (httn://www.iudicium.it/admin/saevi/95/M. ${ }^{\circ} \% 20$ Fabiani.pdf). Como lo señaló en su momento Vignera, La garanzia coslituzionale della terzietá del giudice civile, cit., 1467 y S., con la ley de reforma del art. 111 Const. "el Legislador constitucional ha querido «dirigirse» justamente a la Consulta, solicitándole casi una aplicación del valor de la imparcialidad del juez desvinculada de criterios restrictivos y/o formalistas (como ha ocurrido hasta ahora) e inspirada, en cambio, en el principio de efectividad: el cual favoreciendo la exteriorización y el desarrollo de todas las potencialidades garantistas latentes en las normas constitucionales, permitan «adscribir» a esas normas un significado «fuerte», que pueda tener una incidencia concreta y directa sobre el progreso evolutivo de las instituciones procesales" agregando que "Tomando nota, sin embargo, que también la jurisprudencia constitucional sucesiva a la Ley Constitucional del 23 de noviembre 1999 $\mathrm{N}^{\circ} 2$ se ha revelado insensible a su autorizada exhortación, hay que pensar y esperar que solo un ... .«recambio generacional» en la composición subjetiva de la Corte podrá consentir al «nuevo» art. 111 Const. iabrir finalmente una brecha en esa jurisprudencia!". 


\subsection{La Corte de Casación francesa v su distinto "metro" para determinar la}

imparcialidad "objetiva" en función del tipo de medida

La Corte de Casación francesa, al igual que la Corte Constitucional italiana, (ciertamente dentro del ámbito de su competencia) ha también tenido ocasión de pronunciarse sobre el problemas de si el "cumul du provisoire et du fond par un méme juge" era compatible con el artículo $6.1^{\circ}$ de la Convención de Roma ${ }^{42 .}$

Y lo hizo el mismo día (el 6 de noviembre de 1998) con dos sentencias emitidas, ni más ni menos por la Asamblea Plenaria de la Corte.

La primera, relativa al caso del señor M. Julien, un floricultor que había adquirido una cierta cantidad de abono que luego resultó contaminado, con la consecuencia de que se le murieron todas sus plantas. Con base a una pericia, Julien, se había dirigido al Tribunal de commerce competente, obteniendo de éste una ordenanza de référé-provisión (o sea, una suma a título de indemnización provisional) ${ }^{43}$. La ordenanza fue confirmada por la Corte de Apelación. Iniciado y concluido el proceso de fondo, y apelada la sentencia, uno de los jueces que integraban la Corte de Apelación resultó siendo el mismo que había conocido de la apelación de la ordenanza de référé. Las partes interesadas levantaron la excepción de incompatibilidad de este magistrado por violación del principio de imparcialidad. La cuestión fue desestimada. La misma cuestión fundamentó el recurso de casación.

El otro asunto estaba referido a una saisie conservatoire (un embargo preventivo), al que le siguieron dos référés "colaterales": uno para obtener la reducción de la saisie (con éxito positivo) y otro (con éxito negativo) enderezado a revocar la medida. Iniciado el proceso de fondo, en apelación el asunto fue conocido por una Corte compuesta por uno de los jueces que había visto los référés. Estando el asunto en casación, la excepción de incompatibilidad fue planteada de oficio por la Corte de Casación al conocer del respectivo recurso.

¿Y qué decidió la Corte de Casación? Pues en el primer caso se consideró que sí se había violado la imparcialidad judicial por ser el référé provisión "anticipatorio" (frente al asunto de fondo) ${ }^{44}$ mientras que en el segundo no, por ser meramente "conservatorio" 45 . La doctrina más sensible quedó perpleja ${ }^{46}$, pero lo cierto es que, al menos respecto de las resoluciones "anticipatorias" la Corte de Casación encontró la incompatibilidad en el "cumul du provisoire et du fond par un méme juge".

42 En rigor, el tema se lo planteó la doctrina francesa (y belga) más sensible. No por nada en e libro Les mesures provisoires en droií belge, franjáis et italien. Bruylant, Bruxelles, 1998, una de las cuestiones abordadas a nivel comparado entre Bélgica, Francia e Italia es justamente "Le juge du provisoire el l'impartialité" (Cap. IV, pp. 235-266).

43 El référé-provision es una medida anticipatorio-satisfactiva, para cuya concesión basta que haya un crédito no "seriamente cuestionable" (v. segundo párrafo art. 809 del CPC francés). Sobre este référé v. Јоммі, II référé provisión. Ordinamento francese ed evoluzione della tutela sommaria anticipatoria in Italia, Giappichelli, Tormo, 2005.

44 En concreto, la Sentencia de la Asamblea Plenaria de Casación francesa del 6 de noviembre 1998 se afirma: "qu il en résulte que lorsqu un juge a statué en référé sur une demande tendant á l'attribution d'une provisión en raison du car adere non sérieusement contestable d'une obiigation. i i ne peut ensuite statuer sur le fond du litige ajférent á cette obiigation

45 En la (segunda) Sentencia de la Asamblea Plenaria de Casación francesa del 6 de noviembre 1998 se considera: "que la circonstance qu un magistral statue sur le fond d'une affaire dans iaquelle il a pris préalabiement une mesure conservatoire $n$ implique pas une atteinte á $i$ 'exigence d impartialité appréciée objectivement".

46 Lo refiere SILVESTRI, II référé nell 'esperienza giuridica francese, Giappichelli, Torino, 2005, p. 131 ys. 


\section{PERSPECTIVAS}

No me cabe duda que el postular que la incompatibilidad funcional de ser juez del cautelar y juez del proceso de fondo debe sonar (entre nosotros) un tanto "exótico", pues siempre se nos ha dicho exactamente lo contrario.

De allí que nosotros hayamos asumido como algo "obvio" que el juez del cautelar sea el mismo juez del fondo (tan obvio que el CPC de 1993 ni siquiera lo dice) y que, también, hayamos considerado de lo más normal que el artículo $33^{\circ}$ del CPC señale que las medidas cautelares ante causam deban ser pedidas ante el juez competente para conocer de la "demanda próxima a interponerse", tanto es así que las últimas reformas en materia cautelar (las de la Ley 29384, de junio 2009) hayan estado orientadas (para evitar el fornm shopping doméstico) a que el juez del cautelar ante causam sea exactamente el mismo del fondo.

Y si lo consideramos del todo normal para el proceso civil estatal, pues también nos parecerá del todo normal que ello ocurra a nivel del arbitraje.

Sin embargo, y este ha sido el objetivo del presente trabajo, hay quienes se han planteado la cuestión seriamente y no han podido dejar de reconocer que el fantasma del "prejuzgamiento" existe ${ }^{47}{ }^{48}$. Y existiría incluso si el baricentro del juicio cautelar se hiciera recaer sobre el periculum in mora y el juicio sobre el fumus boni inris viniera concebido no en sentido "positivo" (como lo está en el artículo $610^{\circ} \mathrm{CPC}$, en el que "el Juez concluya con un juicio del tipo «el recurrente tiene o puede tener

Barcelona, 1995, p. 34, se planteaba el tema en términos dubitativos y se hacía las siguientes preguntas: "¿Será capaz el juzgador de decidir sobre la concesión de una medida de [contenido anticipatorio] sin incurrir en alguna extralimitación?; ^seguirá garantizada su neutralidad?". Cfr., también Picó 1 Junor, La imparcialidad judicial y sus garantías. La abstención y recusación. J.M. Bosch. Barcelona, 1998, p. 97, que dedica a la "duda" la nota 267. La nueva Ley de Enjuiciamiento Civil española (L.EC/2000) reconociendo el "problema", sin embargo, le atribuye la competencia cautelar al mismo juez del fondo. La solución viene así justificada en su Exposición de Motivos: "Frente a alguna posición partidaria de atribuir el conocimiento y resolución acerca de las medidas cautelares a un órgano jurisdiccional distinto del competente para el proceso principal, la Ley opta por no separar la competencia, sin perjuicio de que no implique sumisión, respecto del proceso, la actuación de la parte pasiva en el procedimiento relativo a medidas solicitadas antes de la interposición de la demanda. // Esta opción no desconoce el riesgo de que la decisión sobre las medidas cautelares, antes de la demanda o ya en el seno de proceso, genere algunos prejuicios o impresiones en favor o en contra de la posición de una parte, que puedan influir en la sentencia. Pero, además de que ese riesgo existe también al margen de las medidas cautelares, pues el prejuicio podría generarse en la audiencia previa al juicio o tras la lectura de demanda y contestación, esta Ley se funda en una doble consideración. // Considera la Ley, por un lado, que todos los Jueces y Magistrados están en condiciones de superar impresiones provisionales para ir atendiendo imparcialmente a las sucesivas pretensiones de las partes y para atenerse, en definitiva, a los hechos probados y al Derecho que haya de aplicarse. // Y, por otra, no se pierde de vista que las medidas cautelares han de guardar siempre relación con lo que se pretende en el proceso principal e incluso con vicisitudes y circunstancias que pueden variar durante su pendencia, de suerte que es el órgano competente para dicho proceso quien se encuentra en la situación más idónea para resolver, en especial si se tiene en cuenta la posibilidad de alzamiento y modificación de las medidas o de su sustitución por una equitativa contracautela. // Todo esto, sin contar con la menor complejidad procedimental que comporta no separar la competencia". Quizá en esta "justificación" haya un error de fondo: una cosa son las reglas de competencia, que nos permiten individualizar al órgano jurisdiccional (juezórgano) y otra la persona física que se desempeña como juez en ese órgano (juez-persona). De reconocerse la incompatibilidad entre ser el "juezpersona" del cautelar y el de ser el "juez-persona" para conocer del fondo, no implicaría modificación alguna de las reglas de competencia que se refieren al "juez-órgano". http://revistas.pucp.edu.pe/derechoprocesal/node/66). 
razón»"49) sino en sentido meramente "negativo" (es decir, "que «no hay nada que de entrada impida otorgarle la razón al recurrente más tarde», esto es, «la pretensión de fondo no aparece a primera vista desprovista de fundamento»" ${ }^{50}$ ). $\mathrm{Y}$ ello porque incluso un juicio "en negativo" sobre el fumus también podría conducir a que el juez deniegue la cautela basándose en que: "prima facie: la pretensión de fondo carece de fundamento". ¿Podría acaso ese juez conocer "serenamente" del fondo?

Si se tiene presente que, como señala eficazmente Balena, las normas sobre abstención y recusación del juez no tienen como objetivo primario "el interés público a la imparcialidad del juez" sino más bien tienen como "objeto inmediato de tutela", por un lado, "el derecho de las partes de no hacerse juzgar por un juez que podría no estar sereno", y, por el otro, el interés del juez "de sustraerse a una decisión que le podría resultar «incómoda»" 51 , sería bueno no poner en dificultades ni a las partes ni al juez y "objetivamente" establecer que es simplemente incompatible el que el juez (persona) del cautelar sea el mismo que el juez (persona) del fondo.

Ahora, reconocer la "objetiva" incompatibilidad del -como dicen los franceses- cumul du provisoire et du fond par un méme juge puede dar lugar a "complicaciones" a nivel judicial, pero las soluciones existen. No por nada en el ámbito penal hemos creado, en el mismo nivel judicial, a los jueces de las investigaciones preparatorias y los jueces de juzgamiento ${ }^{52}$. ¿Es que eso mismo sería impensable para los procesos "no penales"? ${ }^{53}$

¿Y qué hacer con el "sistema" que hemos consagrado en la LA? Pues al menos considerarlo inadmisible, pues ni siquiera reposa en el gran eslogan que ha acompañado a la reforma: que nos ajustamos a los "estándares internacionales".

De allí que, como mínimo nos debemos ajustar a esos "estándares internacionales" es decir, dejando a las partes que elijan si pedir tutela cautelar a sus árbitros (con todos los riesgos que ello les genera) o ir al juez estatal.

Con el sistema que tenemos, tanto en el proceso estatal como en el arbitraje se condena a la tutela cautelar a no cumplir con su magna función -exaltada hasta el cansancio- de ser elemento insuprimible si es que se quiere asegurar la efectividad del "sistema" de tutela jurisdiccional.

Con todo, el debate -espero- está abierto.

49 Las frases entrecomilladas pertenecen a Bueno ArmijoRodríguez Portugués, Et fumus boni iuris como criterio contrario a! solicitante de medidas cautelares. ¿Un traidor entre los aliados? Comentarios a los autos del TSJ de Cataluña, de 16 y 17 de junio de 2006. sobre suspensión cauteiarísima de! referéndum sobre la reforma del Estatuto de Autonomía de Cataluña, en Revista de Administración Pública. N" 172, 2007 , p. 243.

$50 \quad$ ibid.

51 BALENA, Istituzioni di diritto processtiale civile, I, Cacucci, Bari, 2009, p. 144.

52 El art. 53.1 inc. c) del CPPdel 2004 establece que los jueces deben inhibirse (y si no lo hacen pueden ser recusados) cuando "hubieren intervenido anteriormente como Juez". La disposición no brilla por su claridad (¿qué significa "anteriormente"?, ¿"anteriormente" a qué?), pero la misma distinción funcional entre juez de las investigaciones preparatorias (art. 29) y los jueces de juzgamiento (art. 28) hace entender que ese intervenir "anteriormente" no vale solo cuando se ha intervenido como "juez" en otro "grado", sino también en otra "fase" de las que componen el proceso penal.

53 Si efectivamente se llegara a establecer que las peticiones cautelares deben ser conocidas por un juez (persona) distinto del que conoce del fondo (o si la medida ha sido pedida ante causam, que el juez (persona) del fondo sea un juez (persona) distinto del que conoció de las instancias cautelares) se crearían "problemas" en la organización judicial, sobre todo en aquellos lugares de la República en donde existe un único juzgado (a la sazón "mixto") o una sola Sala (también "mixta"). Pero ese "problema" también se presenta cuando el juez se abstiene o viene recusado y la solución frente a ese "problema" no pasa ciertamente por suprimir ni la abstención ni la recusación. 
